\title{
Analisis Strategi Pemasaran Pada Penyedia Jasa Internet Speedy Di Kec. Taliabu Utara Kab. Pulau Taliabu Prov. Maluku Utara
}

\author{
Merita Margaret \\ J.A.F. Kalangi \\ Lucky F. Tamengkel \\ Jurusan Ilmu Administrasi, Program Studi Administrasi Bisnis \\ Fakultas Ilmu Sosial dan Politik Universitas Sam ratulangi Manado \\ Email: meritamargaret@gmail.com
}

\begin{abstract}
This study aims to analyze the marketing strategy of Speedy Internet Service Providers, especially the marketing mix applied. Then to find out the results of the analysis of Strengths, Weaknesses, Opportunities, and Challenges as well as an overview of the strategy so that it can be applied to increase product sales. By using SWOT, Matrix, EFAS, and IFAS research techniques and Cartecius diagrams. This research uses qualitative methods, namely case studies that produce descriptive data as outlined in words. Data collection techniques in this study the author made a direct visit to conduct personal interviews with Speedy Internet Service Providers and equipped with sales data several years back. The conclusions from the analysis carried out on the company's marketing strategy have carried out the marketing strategy correctly and precisely and in the calculation of the SWOT analysis as outlined in the Cartesius diagram the producers are in the position of quadrant 1, Growth. Which companies can develop, maintain and improve product quality so that people continue to believe in the products provided.
\end{abstract}

Keywords: Marketing Strategy, Marketing Mix, SWOT Analysis, EFAS Matrix, IFAS Matrix, Cartecius Diagram

\section{Pendahuluan}

Strategi pemasaran biasanya dikenal dengan bauran pemasaran atau disebut juga dengan .Marketing Mix. yang terdiri dari: Product (produk), Promotion (promosi), Price (harga), dan Place (distribusi), yang pada hakekatnya strategi ini digunakan untuk meningkatkan volume penjualan. Namun dalam pemasaran jasa atau services marketing, masih ada 4P yang lain yaitu Process, People, Physical Evidence dan Productivity \& Quality.
Menurut Kotler (2010), pemasaran adalah suatu proses sosial dimana melalui proses tersebut individu dan kelompok mendapatkan apa yang dibutuhkan dan diinginkan dengan menciptakan, menawarkan dan secara bebas mempertukarkan produk dan jasa yang bernilai dengan pihak lain. Pemasaran sebagai proses mendefinisikan, mengantisipasi, menciptakan, serta memenuhi kebutuhan dan keinginan pelanggan atas barang dan jasa (David, 2014). 
Tentunya didalam memperoleh konsumen yang loyal terhadap suatu merek tertentu, speedy haruslah memiliki kelebihan atau keunggulan tertentu yang tidak dimiliki oleh para pesaingnya. Dengan kata lain, untuk mencapai keberhasilan dalam persaingan maka setiap bisnis dituntut untuk membangun strategi yang tepat dan unggul dibandingkan dengan strategi yang dibangun oleh pesaingnya. Maka perlunya bauran pemasaran yang baik dari PT Telkom dapat membuka peluang untuk terus berkembang sehingga dapat mencapai tujuan dari usaha yang sedang dijalani yaitu meningkatkan penjualan, memuaskan konsumen, dan mendapatkan keuntungan.

Dengan adanya peningkatan kebutuhan akses internet di kalangan masyarakat Kec. Taliabu Utara baik untuk melakukan kegiatan ekonomi ataupun hannya sekedar mencari informasi menyebabkan banyak di temui penyediapenyedia jasa internet seperti Radnet, Indosatnet, Telkomnet, D-net, Speedy, dan juga masih banyak lainnya.

Masing-masing penyedia jasa internet tersebut saling berlomba untuk dapat menarik konsumen baik melalui harga, kecepatan, fasilitas, yang di tawarkan ataupun kemudahan-kemudahan lainnya.

Bagi setiap perusahaan termasuk penyedia jasa internet, konsumen adalah faktor penting selain kompetitor. Dengan adanya banyak pilihan penyedia jasa internet, konsummen juga tentunya menjadi semakin kritis dalam mengambil keputusan menggunakan.
Menyadari pentingnya peranan konsumen dan strategi pemasaran pada penyedia Speedy Internet. Hal ini disadari pula oleh masyarakat Kec. Taliabu Utara yang menggunakan Internet Speedy untuk memberi jasa pelayanan internet dan dituntut untuk secara terus menerus meningkatkan kualitas pelayanan dan kualitas produk untuk menciptakan kepuasan pelanggan.

Dari latar belakang yang di uraikan di atas, penulis tertarik untuk melakukan penelitian di kepulauan taliabu utara mengenai produk speedy. Penulis dalam hal ini menganalisis strategi pemasaran pada penyedia jasa internet Speedy. dan menuangkannya dalam skripsi dengan judul: "Analisis Strategi Pemasaran Pada Penyedia Jasa Internet Speedy Di Kecamatan Taliabu Utara Kab. PULAU Taliabu"

\section{Produk Dan Jasa}

Kotler (2012) mengemukakan bahwa produk adalah setiap apa saja yang dapat ditawarkan di pasar untuk mendapatkan perhatian, pemakaian atau konsumsi yang dapat memenuhi keinginan atau kebutuhan. Produk meliputi: benda fisik, jasa, orang, tempat, organisasi, dan gagasan. Menurut Lovelock (2017), jasa adalah tindakan atau kinerja yang ditawarkan suatu pihak kepada pihak lainnya, walaupun prosesnya mungkin terkait dengan produk fisik, kinerjanya pada dasarnya tidak nyata dan biasanya tidak menghasilkan kepemilikan atas faktor-faktor produksi. 


\section{Pemasaran Jasa}

Industri jasa pada saat ini merupakan sektor ekonomi yang sangat besar dan tumbuh sangat pesat. Pertumbuhan tersebut selain diakibatkan oleh pertumbuhanjenis jasa yang sudah ada sebelumnya, juga disebabkan oleh munculnya jenis jasa baru, sebagai akibat dari tuntutan dan perkembangan teknologi. Dipandang dari konteks globalisasi, pesatnya pertumbuhan bisnis jasa antar negara ditandai dengan meningkatnya intensitas pemasaran lintas Negara serta terjadinya aliansi berbagai penyedia jasa di dunia. Perkembangan tersebut pada akhirnya mampu memberikan tekanan yang kuat terhadap perombakan regulasi, khususnya pengenduran proteksi dan pemanfaatan teknologi baru yang secara langsung akan berdampak kepada menguatnya kompetisi dalam industry (Lovelock, 2014). Kondisi ini secara langsung menghadapkan para pelaku bisnis kepada permasalahan persaingan usaha yang semakin tinggi. Mereka dituntut untuk mampu mengidentifikasikan bentuk persaingan yang akan dihadapi, menetapkan berbagai standar kinerjanya serta mengenali secara baik para pesaingnya.

\section{Speedy}

Speedy adalah brand dari layanan akses internet end-to-end untuk penggunaan di residensial atau bisnis kecil dan menengah yang berbasis akses kabel tembaga yang menggunakan teknologi Asymmetric Digital Subscriber Line (ADSL). Layanan ini memberikan jaminan kecepatan sesuai dengan paket layanan yang digunakan pelanggan sampai ke BRAS (Broadband Remote Acces Server) dengan pilihan kecepatan akses mulai dari 384 kbps hingga 3 Mbps per line. Sebagai perbandingan, kecepatan akses dial-up yang digunakan oleh layanan Telkomnet Instan adalah 56 kbps per line. (www.telkomspeedy.com).

\section{Internet}

Internet merupakan hubungan antar berbagai jenis komputer dan jaringan di dunia yang berbeda sistem operasi maupun aplikasinya di mana hubungan tersebut memanfaatkan kemajuan media komunikasi (telepon dan satelit) yang menggunakan protokol standar dalam berkomunikasi yaitu protokol TCP/IP yang berisikan informasi dan sebagai sarana komunikasi data yang berupa suara, gambar, video dan juga teks. (Nurul, 2010).

\section{Metode Penelitian}

Dalam penelitian ini penulis melakukan penelitian dengan metode kualitatif. Penelitian yang menggunakan pendekatan kualitatif bertujuan menggali atau membangun satu proposi atau menjelaskan makna dibalik realita. Peneliti berpijak dari realita atau peristiwa yang berlangsung di lapangan.

Metode Observasi merupakan metode pengamatan yang didukung dengan pengumpulan dan pencatatan data secara sistematis terhadap obyek yang akan diteliti. Dalam konteks penelitian ini, metode observasi digunakan agar pokok permasalahan yang ada dapat diteliti secara 
langsung pada penyedia jasa internet speedy.

Dalam penelitian ini penulis akan mewawancari pihak yang terkait yaitu pihak-pihak yang menyediakan jasa internet speedy.

Dokumen merupakan catatan peristiwa yang sudah berlalu yang berbentuk lisan, gambar atau karya-karya monumental dari seseorang. Jadi yang dimaksud dengan studi dokumenter yaitu salah satu metode pengumpulan data yang digunakan metodelogi penelitian sosial untuk menelusuri data historis.

Dalam riset kepustakaan ini penulis membaca dan mempelajari segala bentuk tulisan baik buku, artikel, majalah, koran dan informasi tertulis lainnya yang berhubungan dengan penelitian ini.

Pada penelitian ini digunakan salah satu alat analisa yaitu metode SWOT (Strenght, Weakness, Opportunity, Threats). SWOT adalah suatu bentuk analisis didalam manajemen perusahaan atau dalam organisasi yang secara sistematis dapat membantu dalam usaha penyusunan suatu rencana yang matang untuk mencapai tujuan, baik tujuan jangka pendek maupun panjang.

Tabel 3.1

Penentuan Bobot Faktor Internal dan Eksternal

\begin{tabular}{ccccc}
\hline Faktor-Faktor & Skala & & $\mathrm{S}$ & \\
Strategi Internal & Priorita & Konstant & $\mathrm{P}$ & Bobo \\
Eksternal & $\mathrm{s}(\mathrm{SP})$ & $\mathrm{a}(\mathrm{K})$ & $\mathrm{x}$ & $\mathrm{t}$ \\
& & $\mathrm{K}$ & \\
\hline Kekuatan Dan & & & \\
Kelemahan & & \\
\hline 1. & & \\
\hline 2. & & \\
\hline D. Dst.. & & \\
\hline TOTAL SP X K
\end{tabular}

\begin{tabular}{c}
\hline $\begin{array}{c}\text { PELUANG Dan } \\
\text { ANCAMAN }\end{array}$ \\
\hline 1. \\
\hline 2. \\
\hline TOTAL SP X K \\
\hline
\end{tabular}

Cara menentukan bobot setiap indikator dari faktor-faktor internal maupun eksternal yaitu dengan menggunakan skala prioritas mulai dari 4 (sangat penting), 3 (penting), 2 (cukup penting), 1 (tidak peting). Sedangkan pada variabel bersifat negatif diberi nilai sebaliknya yaitu 1 (sangat penting), 2 (penting), 3 (cukup penting), 4 (tidak penting). Kemudian kalikan nilai skala prioritas (SP) dengan konstanta (K). Penentuan nilai konstanta didasarkan pada nilai tertinggi yaitu 4 dengan asumsi bahwa semua indikator dianggap baik. Masing-masing nilai SP x K dibagi dengan total nilai SP $\mathrm{x} K$ untuk memperoleh nilai bobot.

Tabel 3.2

Perhitungan Analisis SWOT

\begin{tabular}{|c|c|c|c|}
\hline Faktor Strategi & Bobot & Rating & Nilai \\
\hline \multirow{4}{*}{$\begin{array}{l}\text { Internal : } \\
\text { Strenght (S) } \\
\text { Weakness (W) }\end{array}$} & S1 $(0,0-$ & & $\mathrm{S} 1 \times \mathrm{S} 2=$ \\
\hline & $1,0)$ & $\mathrm{S} 2(1-4)$ & $\mathrm{S} 3$ \\
\hline & W1 $(0,0-$ & W2 (1-4) & W1 x W3 \\
\hline & $1,0)$ & & $=\mathrm{W} 3$ \\
\hline Total & 1 & & \\
\hline \multirow{4}{*}{$\begin{array}{l}\text { Eksternal: } \\
\text { Opportunity (O) } \\
\text { Threats ( T) }\end{array}$} & O1 $(0,0-$ & & $\mathrm{O} 1 \times \mathrm{O} 2$ \\
\hline & $1,0)$ & O1 (1-4) & $=03$ \\
\hline & T1 (0,0- & & $\mathrm{T} 1 \times \mathrm{T} 2=$ \\
\hline & $1,0)$ & & $\mathrm{T} 3$ \\
\hline Total & 1 & & \\
\hline
\end{tabular}

1. Bobot dari internal dan eksternal antara 0,0 sampai dengan 1,0

2. Rating dari internal dan eksternal antara 1 sampai dengan 4

3. Nilai dari internal dan eksternal adalah hasil perkalian antara bobot dengan rating. 


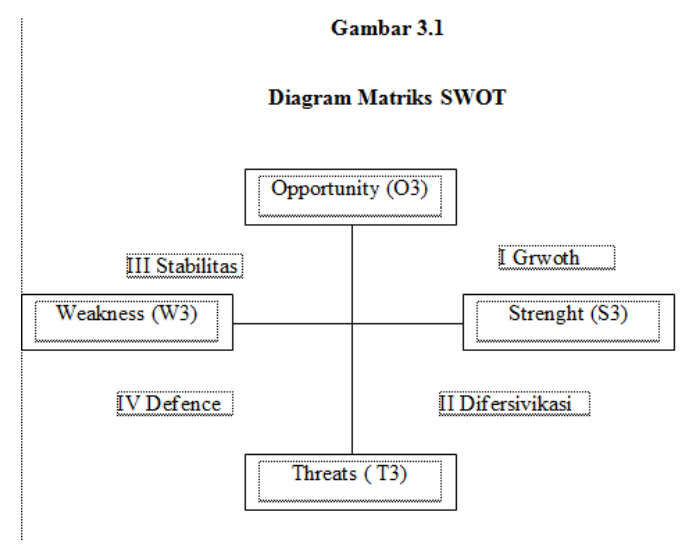

Rekomendasi :

Kuadran I : Ini merupakan situasi yang meguntungkan. Perusahaan tersebut memiliki peluang dan kekuatan sehingga dapat memanfaatkan peluang yang ada. Strategi yang harus diterapkan dalam kondisi ini adalah mendukung kebijakan pertumbuhan yang agresif (Growth oriented strategy).

Kuadran II : Meskipun menghadapkan berbagai ancaman, perusahaan ini masih memiliki kekuatan dari segi internal. Strategi yang harus diterapkan adalah menggunakan kekuatan untuk memanfaatkan peluang jangka panjang dengan cara strategi diversivikasi.

Kuadran III : perusahaan menghadapi peluang pasar yang sangat besar, tetapi dilain pihak, ia menghadapi beberapa kendala/kelemahan internal. Fokus strategi perusahaan ini adalah meminimalkan masalah-masalah internal perusahaan sehingga dapat merebut peluang pasar yang lebih, dengan strategi stabilitas.

Kuadran IV : Ini merupakan situasi yang sangat tidak menguntungkan perusahaan, yang dimana perusahaan tersebut mengalami berbagai ancaman dan kelemahan internal. harus segera mencari strategi bertahan (Defence Strategy).

Tabel 3.3

Matrik Analisis SWOT

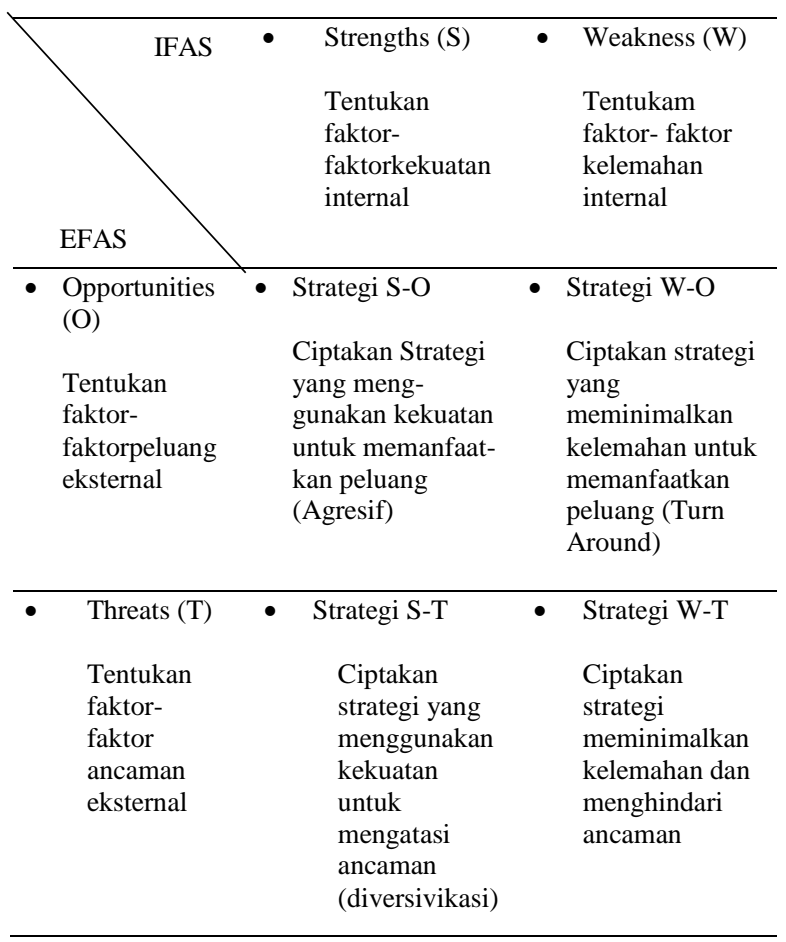

1. Strategi SO (Strenghts Opportunities) = Kuadran 156 Strategi SO merupakan strategi yang dibuat berdasarkan jalan pemikiran objek, yaitu dengan menggunakan seluruh kekuatan untuk merebut dan memanfaatkan peluang sebesar-besarnya.

2. Strategi ST (Strenghts Threats) = Kuadran 2 Strategi ST merupakan strategi yang menggunakan kekuatas yang dimiliki objek untuk mengatasi ancaman.

3. Strategi WO (Weaknesses Opportunities) $=$ Kuadran 3 Strategi WO ini ditetapkan berdasarkan pemanfaatan peluang yang ada dengan cara meminimalkan kelemahan yang ada. 
4. Strategi WT (Weaknesses Threats) = Kuadran 4 Strategi WT didasarkan pada kegiatan yang bersifat defensif dan berusaha meminimalkan kelemahankelemahan yang ada serta menghindari ancaman.

\section{Hasil Penelitian Dan Pembahasan}

Pada bagian ini akan dihadirkan beberapa data primer dari hasil wawancaralangsug yang dilakukan kepada objek penelitian. Objek penelitian adalah pihak internal yaitu Bpk. Muhamad Ali selaku Kepala Desa di Desa Tikong dan juga sebagai penyedia jasa internet speedy.

\section{Analisis SWOT}

Analisis SWOT atau TOWS adalah alat teknik penelitian kualitatif untuk mengidentifikasi berbagai faktor secara sistematis untuk merumuskan strategi dalam meningkatkan tingkat volume penjualan produk sebuah perusahaan.

Tabel 4.1

Penentuan Bobot Faktor-Faktor Kekuatan dan

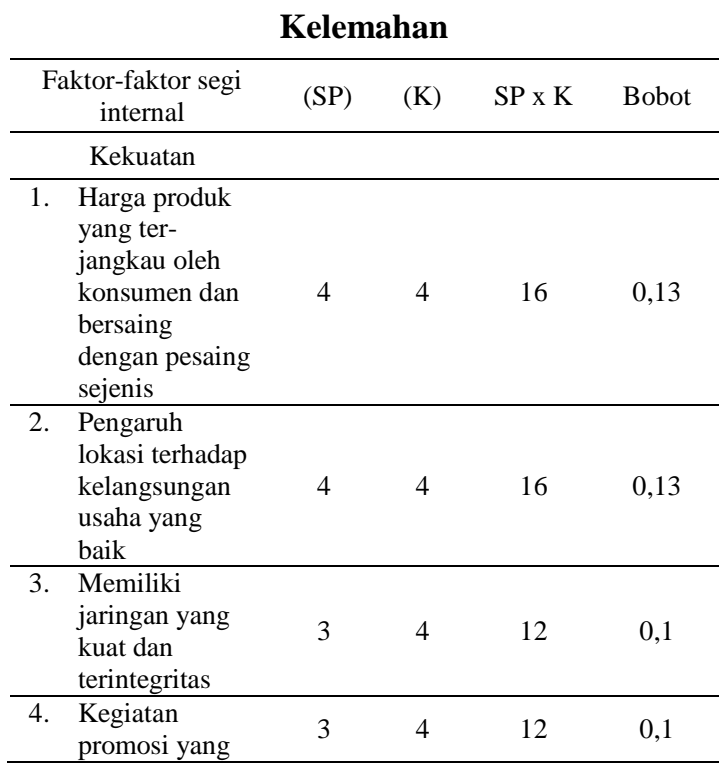

\begin{tabular}{|c|c|c|c|c|c|}
\hline & $\begin{array}{l}\text { dilakukan } \\
\text { mencakupi } \\
\text { seluruh aspek }\end{array}$ & & & & \\
\hline 5. & $\begin{array}{l}\text { Reputasi dan } \\
\text { citra positif dari } \\
\text { masyarakat }\end{array}$ & 3 & 4 & 12 & 0,1 \\
\hline 6. & $\begin{array}{l}\text { voucher yang } \\
\text { di jual telah } \\
\text { terbukti asli } \\
\text { belum pernah } \\
\text { dipakai/bekas }\end{array}$ & 3 & 4 & 12 & 0,1 \\
\hline 7. & $\begin{array}{l}\text { Penyedia jasa } \\
\text { internet } \\
\text { memiliki } \\
\text { sarana fisik dan } \\
\text { serta memiliki } \\
\text { fasilitas dan } \\
\text { peralatan yang } \\
\text { lengkap }\end{array}$ & 3 & 4 & 12 & 0,1 \\
\hline \multicolumn{6}{|c|}{ Kelemahan } \\
\hline 1. & $\begin{array}{l}\text { Masih adanya } \\
\text { sumberdaya } \\
\text { konsumen yang } \\
\text { kurang } \\
\text { kompeten }\end{array}$ & 3 & 4 & 12 & 0,1 \\
\hline 2. & $\begin{array}{l}\text { Usaha } \\
\text { penyediaan } \\
\text { internet speedy } \\
\text { baru di bangun } \\
\text { pada tahun } \\
2016 \text { sehingga } \\
\text { tergolong } \\
\text { sebagai usaha } \\
\text { baru }\end{array}$ & 2 & 4 & 8 & 0,07 \\
\hline 3. & $\begin{array}{l}\text { Lokasi tempat } \\
\text { usaha dengan } \\
\text { pusat kota yang } \\
\text { sangat jauh } \\
\text { sehingga susah } \\
\text { jika ada } \\
\text { kerusakan }\end{array}$ & 2 & 4 & 8 & 0,07 \\
\hline & Total SP x K & & & 120 & 1.0 \\
\hline
\end{tabular}

Berdasarkan tabel 4.1 penentuan bobot faktor-faktor kekuatan dan kelemahan pada tabel diatas maka dapat dibuat faktor-faktor strategi yang hasilnya ditunjukkan kepada tabel IFAS disusun untuk merumuskan faktor-faktor strategi internal tersebut dalam kerangka kekuatan (strength) dan kelemahan (weakness) perusahaan.

Tabel 4.2

IFAS (Internal Factor Analysis Summary)

\begin{tabular}{|c|c|c|c|}
\hline Faktor-faktor Eksternal & Bobot & Rating & Skor \\
\hline Kekuatan & & & \\
\hline $\begin{array}{l}\text { 1. Harga produk yang } \\
\text { terjangkau oleh konsumen } \\
\text { dan bersaing dengan pesaing } \\
\text { sejenis. }\end{array}$ & 0,13 & 4 & 0,52 \\
\hline 2. Pengaruh lokasi terhadap & 0,13 & 4 & 0,52 \\
\hline
\end{tabular}




\begin{tabular}{|c|c|c|c|}
\hline $\begin{array}{l}\text { kelangsungan usaha yang } \\
\text { baik. }\end{array}$ & 0,1 & 3 & 0,3 \\
\hline 3. Memiliki jaringan yang kuat & 0,1 & 3 & 0,3 \\
\hline dan terintegritas & 0,1 & 3 & 0,3 \\
\hline $\begin{array}{lrr}\text { 4. Kegiatan } & \text { promosi yang } \\
\text { dilakukan } & \text { mencakupi }\end{array}$ & 0,1 & 3 & 0,3 \\
\hline $\begin{array}{l}\text { seluruh aspek. } \\
\text { 5. Reputasi dan citra positif } \\
\text { dari masyarakat. }\end{array}$ & 0,1 & 3 & 0,3 \\
\hline $\begin{array}{l}\text { 6. voucher yang di jual telah } \\
\text { terbukti asli belum pernah } \\
\text { dipakai/bekas }\end{array}$ & & & \\
\hline $\begin{array}{l}\text { 7. Penyedia jasa internet } \\
\text { memiliki sarana fisik dan } \\
\text { serta memiliki fasilitas dan } \\
\text { peralatan yang lengkap }\end{array}$ & & & \\
\hline Sub Total & 0,76 & & 2,54 \\
\hline \multicolumn{4}{|l|}{ Kelemahan } \\
\hline $\begin{array}{l}\text { 1. Masih adanya sumberdaya } \\
\text { konsumen yang kurang }\end{array}$ & 0,1 & 3 & 0,3 \\
\hline kompeten & 0,7 & 2 & 1,4 \\
\hline $\begin{array}{l}\text { 2. Usaha penyediaan internet } \\
\text { speedy baru di bangun pada } \\
\text { tahun } 2016 \quad \text { sehingga }\end{array}$ & 0,7 & 2 & 1,4 \\
\hline \multicolumn{4}{|l|}{$\begin{array}{l}\text { 3. Lokasi tempat usaha dengan } \\
\text { pusat kota yang sangat jauh } \\
\text { sehingga susah jika ada } \\
\text { kerusakan }\end{array}$} \\
\hline \multicolumn{4}{|l|}{ Sub Total } \\
\hline Total & 1.0 & & 3.12 \\
\hline
\end{tabular}

Berdasarkan hasil perhitungan, faktor internal kekuatan yang dimiliki penyedia jasa internet lebih besar dari faktor kelemahan nya yaitu sebesar 1.96, yang diman angka 1.96 merupakan selisih dari total kekuatan sebesar 2.54 dengan total kelemahan sebesar 0.58, dan untuk faktor eksternal peluang yang dimiliki penyedia jasa internet lebih besar dari faktor ancaman nya yaitu sebesar 1.9 yang dimana merupakan selisih dari total peluang sebesar 2.5 dengan total ancaman sebesar 0.6. Dari perhitungan tersebut dapat diperoleh formulasi strategi pemasaran yang sesuai .

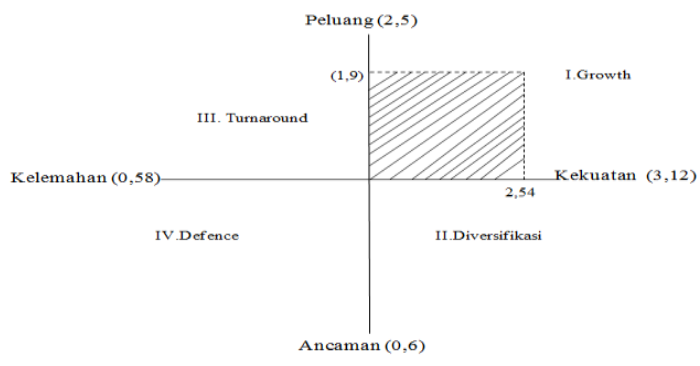

Gambar 4.1 Diagram Cartesius

Berdasarkan diagram cartecius diatas, sangat jelas menujukkan bahwa penyedia jasa internet speedy telah berada pada jalur yang tepat yaitu di kuadran 1 yang menunjukkan bahwa usahanya masih tergolong usaha yang berkembang. Penyedia jasa internet speedy memang masih tergolong usaha berkembang dikarenakan baru berdiri 3 tahun jika di bandingkan dengan usaha lain dibidang sejenis. Meskipun masih dalam usaha berkembang, penyedia jasa internet harus memperhatikan peluang dan ancaman baik dari internal maupun eksternal. Dengan memperhatikan faktor-faktor yang sudah dijelaskan tentu akan meningkatkan pertumbuhan pemasaran usaha yang akan meningkatkan penjualan.

\section{Matriks SWOT}

Matrik SWOT merupakan matrik yang disusun menggunakan variabelvariabel kekuatan, kelemahan, peluang dan ancaman yang diidentifikasi dalam faktorfaktor strategi internal faktor strategi eksternal. Matrik SWOT ini menggambarkan bagaimana peluang dan ancaman dari lingkungan eksternal perusahaan dapat disesuaikan dengan kekuatan dan kelemahan yang dimiliki 
perusahaan. Analisis dengan menggunakan model matrik SWOT ini menggunakan data yang diperoleh dari tabel fakor strategi internal dan faktor strategi eksternal Penyedia jasa internet speedy.

\section{Tabel 4.3}

\section{Matriks SWOT}

\begin{tabular}{|c|c|c|}
\hline EFAS & $\begin{array}{l}\text { Strength (S) : } \\
\text { 1. Harga produk } \\
\text { yang terjangkau } \\
\text { oleh konsumen } \\
\text { dan bersaing } \\
\text { dengan pesaing } \\
\text { sejenis. } \\
\text { 2. Pengaruh lokasi } \\
\text { terhadap } \\
\text { kelangsungan } \\
\text { usaha yang baik. } \\
\text { 3. Memiliki jaringan } \\
\text { yang kuat dan } \\
\text { terintegritas } \\
\text { 4. Kegiatan promosi } \\
\text { yang dilakukan } \\
\text { mencakupi } \\
\text { seluruh aspek. } \\
\text { 5. Reputasi dan citra } \\
\text { positif dari } \\
\text { masyarakat. } \\
\text { 6. voucher yang di } \\
\text { jual telah terbukti } \\
\text { asli belum pernah } \\
\text { dipakai/bekas } \\
\text { 7. Penyedia jasa } \\
\text { internet memiliki } \\
\text { sarana fisik dan } \\
\text { serta memiliki } \\
\text { fasilitas dan } \\
\text { peralatan yang } \\
\text { lengkap } \\
\end{array}$ & $\begin{array}{l}\text { Weakness (W): } \\
\text { 1. Masih adanya } \\
\text { sumberdaya } \\
\text { konsumen yang } \\
\text { kurang kompeten } \\
\text { 2. Usaha } \\
\text { penyediaan } \\
\text { internet speedy } \\
\text { baru di bangun } \\
\text { pada tahun } 2016 \\
\text { sehingga } \\
\text { tergolong sebagai } \\
\text { usaha baru } \\
\text { 3. Lokasi tempat } \\
\text { usaha dengan } \\
\text { pusat kota yang } \\
\text { sangat jauh } \\
\text { sehingga susah } \\
\text { jika ada } \\
\text { kerusakan }\end{array}$ \\
\hline $\begin{array}{l}\text { Opportunities } \\
\text { (O) : } \\
\text { 1. Citra positif } \\
\text { dari } \\
\text { masyarakat } \\
\text { yang } \\
\text { menimbulkan } \\
\text { kepercayaan } \\
\text { terhadap } \\
\text { penyedia jasa } \\
\text { internet } \\
\text { 2. Kesadaran } \\
\text { masyarakat } \\
\text { akan } \\
\text { pentingnya } \\
\text { Komunikasi. } \\
\text { 3. Pengaruh } \\
\text { lokasi } \\
\text { terhadap } \\
\text { kelangsungan } \\
\text { usaha yang } \\
\text { baik. } \\
\text { 4. voucher yang } \\
\text { diciptakan } \\
\text { penyedia jasa } \\
\end{array}$ & $\begin{array}{l}\text { Strategi SO : } \\
\text { 1. Mempartahankan } \\
\text { dan meningkatkan } \\
\text { kualitas produk } \\
\text { agar masyarakat } \\
\text { terus percaya dan } \\
\text { meningkatkan } \\
\text { citra positif } \\
\text { penyedia jasa } \\
\text { internet. } \\
\text { 2. Memperdalam } \\
\text { jalinan dengan } \\
\text { mitra guna } \\
\text { menciptakan } \\
\text { hubungan yang } \\
\text { baik. } \\
\text { 3. Penyedia jasa } \\
\text { internet membuat } \\
\text { promosi yang } \\
\text { menarik untuk } \\
\text { meningkatkan } \\
\text { kesadaran } \\
\text { masyarakat akan } \\
\text { pentingnya } \\
\text { komunikasi. }\end{array}$ & $\begin{array}{l}\text { Strategi WO : } \\
\text { 1. Penyedia jasa } \\
\text { internet } \\
\text { mengadakan } \\
\text { penyamaan visi } \\
\text { misi usaha kepada } \\
\text { penyedia jasa } \\
\text { internet lainnya } \\
\text { melalui pelatihan } \\
\text { Sehingga } \\
\text { tercapainya tujuan } \\
\text { usaha guna } \\
\text { menigkatkan } \\
\text { kepercayaan } \\
\text { Masyarakat } \\
\text { terhadap usahanya } \\
\text { masing-masing }\end{array}$ \\
\hline
\end{tabular}

\begin{tabular}{|c|c|c|}
\hline $\begin{array}{l}\text { internet bisa } \\
\text { digunakan } \\
\text { sebagai alat } \\
\text { komunikasi } \\
\text { didaerah } \\
\text { manapun. } \\
\text { 5. Teknologi } \\
\text { yang } \\
\text { semakin } \\
\text { pesat } \\
\text { membuat } \\
\text { masyarakan } \\
\text { membutuhka } \\
\text { n jaringan } \\
\text { yang } \\
\text { stabil/baik }\end{array}$ & & \\
\hline $\begin{array}{l}\text { Threat }(\mathbf{T}) \text { : } \\
\text { 1. Persaingan } \\
\text { yang tinggi } \\
\text { antara usaha } \\
\text { yang menjual } \\
\text { produk } \\
\text { sejenis } \\
\text { 2. Perilaku } \\
\text { konsumen } \\
\text { yang tidak } \\
\text { bisa } \\
\text { dipastikan } \\
\text { dalam } \\
\text { memilih } \\
\text { produk. } \\
\text { 3. Mitra usaha } \\
\text { yang tidak } \\
\text { kooperatif } \\
\text { dalam } \\
\text { menyelesaika } \\
\text { n } \\
\text { kewajibanny } \\
\text { a }\end{array}$ & $\begin{array}{l}\text { Strategi ST : } \\
\text { 1. Terus melakukan } \\
\text { inovasi dan } \\
\text { meningkatkan } \\
\text { kualitas produk } \\
\text { guna mengungguli } \\
\text { persaingan antara } \\
\text { usaha sejenis. } \\
\text { 2. Meningkatkan dan } \\
\text { memperluas } \\
\text { jaringan } \\
\text { pemasaran agar } \\
\text { dapat } \\
\text { mempengaruhi } \\
\text { konsumen dalam } \\
\text { pengambilan } \\
\text { keputusan } \\
\text { pemilihan produk } \\
\text { 3. Usaha-usaha di } \\
\text { berbagai daerah } \\
\text { dapat } \\
\text { meningkatkan } \\
\text { fungsi } \\
\text { pengawasan untuk } \\
\text { menghindari / } \\
\text { mengurangi mitra } \\
\text { yang tidak } \\
\text { kooperatif. } \\
\end{array}$ & $\begin{array}{l}\text { Strategi WT: } \\
\text { 1. Penyedia jasa } \\
\text { internet terus } \\
\text { meningkatkan } \\
\text { kualitas hubungan } \\
\text { internal dan } \\
\text { eksternal usaha } \\
\text { agar mengungguli } \\
\text { persaingan dengan } \\
\text { usaha sejenis }\end{array}$ \\
\hline
\end{tabular}

Berdasarkan hasil analisis SWOT penyedia jasa internet memiliki kekuatan yang dapat dipakai pada strategi tertentu serta memanfaatkan peluang yang tepat serta secara bersamaan sehingga dapat meminimalisir atau menghindari kelemahan dan ancaman yang ada. Posisi ini sangat menguntungkan perusahaan dengan memperbaiki kondisi di atas rata-rata kemampuan sehingga penyedia jasa internet dapat mengendalikan para pesaing yang ada maupun pesaing yang terbilang kuat. 


\section{Kesimpulan}

Dari penelitian diatas maka dapat diambil kesimpulan, dalam melakukan strategi pemasaran Penyedia Jasa Internet Speedy menerapkan segmentasi, targetting dan positioning dengan benar dan tepat.

Berdasarkan analisis internal dan eksternal perusahaan beserta diagram Cartesius dapat diperoleh bahwa yang menjadi strategi utama dari Penyedia Jasa Internet Speedy adalah strategi Growth. Yang mana Penyedia Jasa Internet Speedy dapat mempertahankan dan meningkatkan kualitas produk agar masyarakat terus percaya pada produk mereka. Lalu memperdalam jalinan dengan mitra guna menciptakan hubungan yang baik serta membuat promosi yang menarik untuk meningkatkan kesadaran masyarakat akan pentingnya menjaga komunikasi.

Berdasarkan matriks SWOT maka dapat disimpulkan beberapa pengembangan melalui pertimbangan faktor internal dan eksternal usaha yang dapat bermanfaat bagi kemajuan Penyedia Jasa Internet Speedy.

\section{Saran}

Berdasarkan pengamatan penulis mengenai strategi pemasaran produk yang di terapkan Penyedia Jasa Internet Speedy, maka adapun saran yang ingin penulis sampaikan adalah berikut:

Untuk meningkatkan pengembangan, Penyedia Jasa Internet Speedy terus meningkatkan kualitas produk guna menarik kepercayaan agar terus digunakan oleh konsumen dan membuat diferensiasi produk.
Dengan pengembangan produk baru akan menimbulkan ketertarikan konsumen pada inovasi produk tersebut. Terus meningkatkan kegiatan promosi semenarik mungkin dari promosi harga maupun membuat iklan guna membuat konsumen tertarik pada produk perusahaan yang akan meningkatkan volume penjualan.

Peneliti menyadari masih banyak kekurangan dalam penulisan, maka diharapkan untuk peneliti selanjutnya dapat melanjutkan penelitian ini dengan mengukur dari segi aspek yang berbeda dan metodelogi yang berbeda.

\section{Daftar Pustaka}

David. A. 2013. Manajemen Pemasaran Strategi. Edisi 8, Jilid 1. Jakarta: Salemba Empat.

Alma, Buchari, (2013): Manajemen Pemasaran dan Pemasaran Jasa.Alfabeta,

Cangara, David. Pengertian Ilmu Komunikasi, Jakarta: PT. Raja Grafindo Persada, 2015

Cangara, Hafied Prof. M.Sc. Ph. D. Perencanaan dan Strategi Komunikasi, Jakarta: PT. Raja Grafindo Persada, 2013

Kotler, Philip \& Armstrong (2012): Marketing Management 14th Edition New Jersey: Pretice Hall.

Kotler.Philip dan Amstrong, PrinsipPrinsip Pemasaran, (Jakarta: Erlangga, Edisi ke-13, Jilid ke-1, 2012.

Kotler, Philip \& Gerry Armstrong, (2014): Principle Of Marketing, 15th edition. New Jersey: Pearson Pretice Hall. 
Kotler, Philip and Kevin Lane Keller, (2012): Marketing Management New Jersey: Pearson Pretice Hall, Inc.

Kotler, Philip and Kevin Lane Keller, (2016): Marketing Management, 15th 